\title{
Seroprevalence of COVID-19 Among Health Care Workers in Primary Health Care Centers in Al-Sader City District, Baghdad, Iraq
}

Raheem Hussein ${ }^{1}$; Faris Lami ${ }^{2}$

${ }^{1}$ Public Health department, Al-Rusafa Health Directorate, Baghdad, Iraq

${ }^{2}$ Ministry of Higher Education and Scientific research, Baghdad, Iraq

Corresponding Author:

Raheem Hussein

Public Health department

Al-Rusafa Health Directorate

Al-Rusafa

Baghdad, 89WG+5P5

Iraq

Phone: 96407706858337

Email: rhhu1965@gmail.com

\section{Abstract}

Background: The SARS-CoV-2 infection produces detectable immune responses in most cases reported to date. A serological test could capture previous asymptomatic infections and help to assess the immune status of a subject. Health care workers are highly vulnerable to COVID-19 infection, and providing personal protective equipment is the primary strategy to prevent disease transmission within the health care setting.

Objective: The aim of this paper was to determinate the seroprevalence of COVID-19 among health care workers in primary health care centers in the AL-Sader city district.

Methods: A cross-sectional study was conducted in 9 primary health care centers, which were selected using a cluster random sampling technique from November 1, 2020, to December 31, 2020.

Results: A total of 470 participants were enrolled in the study; 101 (21.5\%) of them had a history of COVID-19 infection, and $76(16.1 \%)$ were diagnosed by polymerase reaction chain. There was a significant association between rapid tests and history of COVID-19 infection $(P<.001)$. Rapid test sensitivity was $56.6 \%$, and specificity was $79.2 \%$. The rapid test was positive in 125 (26.6\%) participants: IgG 104 (83.2\%), IgM 5 (4\%), and both IgG-IgM 16 (12.8\%).

Conclusions: The percent of COVID-19 infection is higher than the expected level among participants. A significant association was found between rapid tests and COVID-19 infection, smoking, comorbidity, personal protective equipment training, and household infection.

(iproc 2022;8(1):e36473) doi: $\underline{10.2196 / 36473}$

\section{KEYWORDS}

COVID-19; cross-sectional; health care workers; infection

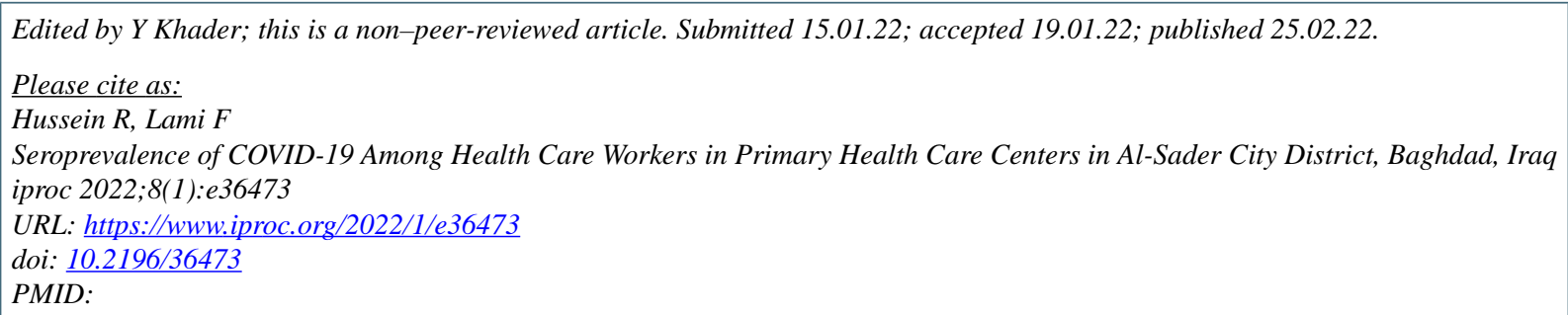


(CRaheem Hussein, Faris Lami. Originally published in Iproceedings (https://www.iproc.org), 25.02.2022. This is an open-access article distributed under the terms of the Creative Commons Attribution License (https://creativecommons.org/licenses/by/4.0/), which permits unrestricted use, distribution, and reproduction in any medium, provided the original work, first published in Iproceedings, is properly cited. The complete bibliographic information, a link to the original publication on https://www.iproc.org/, as well as this copyright and license information must be included. 